\title{
Tip 2 Diyabetik Pulmoner Sarkoidozlu Bir Olguda Steroid Tedavisi Altında Metabolik Kontrolün Sağlanması
}

 \\ Emrah ÇAĞLAR ${ }^{3}$, Taner BAYRAKTAROĞLU ${ }^{2,4}{ }^{\circ}$ \\ ${ }^{1}$ Bülent Ecevit Üniversitesi Tip Fakültesi, Göğüs Hastalıkları Anabilim Dalı, Zonguldak \\ ${ }^{2}$ Bülent Ecevit Üniversitesi Tıp Fakültesi, İç Hastalıkları Anabilim Dalı, Zonguldak \\ ${ }^{3}$ Bülent Ecevit Üniversitesi Tip Fakültesi, Radyoloji Anabilim Dalı, Zonguldak \\ ${ }^{4}$ Bülent Ecevit Üniversitesi Tip Fakültesi, Endokrinoloji ve Metabolizma Hastalıkları Bilim Dalı, Zonguldak \\ Bu makaleye yapılacak atıf: Aydoğan O, Çorakçı BD, Erboy F, Altınsoy B, Çağlar E, Bayraktaroğlu T. Tip 2 Diyabetik pulmoner Sarkoidozlu bir olguda \\ steroid tedavisi altında metabolik kontrolün sağlanması. Türk Diyab Obez 2018;2: 95-100.
}

\begin{abstract}
ÖZET
Tip 2 diyabet tanısı aldıktan sonraki takiplerinde akciğer sarkoidozu tanısı ile steroid tedavisi alırken kronik aktif bir karaciğer hastalı̆̆ı bulunan ve metabolik kontrolünde zorluk yaşanan bir olguyu sunmaktayız.

Otuzaltı yaşında erkek hasta, tip 2 diyabet tanısıyla metformin tedavisi altında metabolik kontrolü iyi iken Löfgren Sendromu tanısı aldı. Akciğer tutulumu nedeniyle steroid tedavisi başlandı. Aktif karaciğer hastalığı da var olduğundan oral antidiyabetikler kullanılamadı. Kliniği ve akciğer bulguları gerilerken hiperglisemisi belirginleşti. Bu nedenle de bazal/bolusinsulin tedavisi ile metabolik kontrol sağlanmaya çalışıldı. Komplikasyonsuz diyabetik olgumuzun steroid dozları azaltılldı̆̆ında kan şekeri değerleri de optimal düzeylerde seyretti.

Yüksek doz ve uzun süre steroid kullanımı ve diabetes mellitus birlikteliği kronik akciğer hastalıklarında kan şekeri kontrolünün bozulmasına ve diabetes mellitusa bağı komplikasyonların artışına neden olabilir. Olgumuzdaki gibi diyabetiklerde tedaviyi aksatmadan steroid dozunun mümkün olan en uygun sürede en düşük doza düşülmesi önerilmektedir. Ayrıca steroid yerine alternatif tedavilerin kullanılması kan şekerinin kontrolünde önemli rol oynayacaktır.
\end{abstract}

Anahtar Sözcükler: Diabetes Mellitus, Insülin, Steroid, Sarkoidoz, Löfgren sendromu

\section{The Improvement of the Metabolic Regulation in a Diabetic Patient With Pulmonary Sarcoidosis Treated With Steroid}

\begin{abstract}
After receiving a diagnosis of type 2 diabetes, he was diagnosed with lung sarcoidosis and steroid treatment, we present a case with chronic active hepatic disease and difficulty in metabolic control.

Thirty-two-year-old male patient was diagnosed with type 2 diabetes and diagnosed with Löfgren's syndrome while metabolic control was good under metformin treatment. Steroid therapy started because of lung involvement. Oral antidiabetics were not used because of active liver disease. Hyperglycemia became evident when clinic and lung findings were improved. For this reason, metabolic control was attempted with basal / bolus insulin therapy.

When steroid doses of uncomplicated diabetic patients are reduced, blood glucose levels were also at optimal levels. High dose, longterm steroid use and diabetes mellitus association may lead to impaired blood glucose control in chronic lung diseases and increased complications. As in our case, it is recommended that the dose of the steroid be lowered to the lowest possible dose in the best possible time, without disrupting the treatment of diabetic patients.In addition, the use of alternative therapies instead of steroids will play an important role in the control of blood glucose levels.
\end{abstract}

Key Words: Diabetes Mellitus, Insulin, Steroid, Sarcoidozis, Löfgren's syndrome

DOI: $10.25048 /$ tjdo.2018.179 


\section{GİRIS}

Sarkoidoz sebebi bilinmeyen ve çeşitli dokularda kazeözsüz granülom formasyonu ile karakterize bir hastalıktır. En sık etkilenen alanlar akciğerler, lenf nodları, deri, göz ve karaciğerdir. Granülomatöz inflamasyon parçalanamayan antijeni temizlemek için konak tarafından yapılan bir girișim olarak kabul edilir. Bu sebeple her sarkoidoz olgusunda tedavi indikasyonu yoktur. Tedavi ihtiyacı mevcut inflamasyonun ilgili dokuda hasar vermeye başladığında ortaya çıkar. Tedavide ilk sıra seçenek ilaç ise glukokortikoidlerdir. Glukokortikoidler güçlü antiinflamatuar özelliğe sahip bir ajan olup birçok solunum yolu hastalığının tedavisinde yaygın olarak kullanılmaktadır. Diğer taraftan glokom, sıvı tutulumu, kan basıncı artışı, kan şekerinde artış, adet düzensizlikleri, ağırlık artışı, peptik ülser, uykusuzluk ve enfeksiyon gibi birçok yan etkileri vardır $(1,2)$.

Glikoz metabolizmasında bozulma en yaygın yan etkilerinden biridir $(1,3)$. Glukokortikoidler sadece diabetes mellitus (DM) tanılıhastalarda hiperglisemide artışyapmakla kalmaz, aynı zamanda glukokortikoid başlanmadan önce hiperglisemi göstermeyen hastalarda da DM'a neden olabilirler. Çoğu vakada hiperglisemik durum geçicidir, ancak bazı hastalarda polidipsi, poliüri ve tekrarlayan enfeksiyonlar gelişebilir. Özellikle yaşllarda, koma da dahil olmak üzere hiperglisemik hiperosmolar durumların ortaya çıkma riski vardır. Uzun vadede, tekrarlayan kan şekeri artışlarının genel yükü, kardiyovasküler riski ve mikrovasküler komplikasyonları artırır $(3,4)$.

Bu raporda tip 2 diyabet ve kronik aktif karaciğer hastalı̆̆ 1 olan bir sarkoidoz olgusunda, steroid tedavisi altında yaşanan metabolik kontrolünde zorluk ve yaklaşım sunulmaktadır.

\section{OLGU}

Otuzaltı yaşında erkek hasta ateşlenme, kas ağrısı, kuru öksürük, eforla nefes darlığı, deride nodüler tarzda kızarıklıklar nedeniyle başvurdu. Yaklaşık 2,5 yıl önce işyerindeki sağlık kontrolleri sırasında kan şekeri yükseklikleri saptanmış ve $180 \mathrm{mg} / \mathrm{dl}$ seviyelerini geçmemekteymiş. Tedavi için verilen metformin 2x1000 $\mathrm{mg}$ /gün kullanırken şekerleri bu değerleri geçmemiş.

Günlük yarım paket ve 18 yıldır sigara kullanımı mevcuttu. Soy geçmişinde baba 62 yaşında diabetes melitus ve kalp yetmezliğinden vefat etmiş. Ablası diabetes mellitus ve böbrek yetmezliği tanısıyla tedavi görmekteymiş.

Fiziki muayenesinde boy $188 \mathrm{~cm}$, ağırlığ $84 \mathrm{~kg}$, bel çevresi $102 \mathrm{~cm}$, vücut kitle indeksi 23,8 kg/m2, kan basınc1 116/75 mmHg, nabız 84 dakika sayısı ve ritmikti. Deride özellikle ekstansör yüzeylerde eritema nodosumla uyumlu lezyonlar mevcuttu. Tiroid evrela diffüzdü. Servikal patolojik lenfadenomegali saptanmadı. Akciğerde bilateral bazallerde inspiryum sonu ince ralleri mevcuttu. Kalp sesleri normaldi, ek ses ve üfürüm saptanmadı. Karaciğer kot kavsini geçmiyordu. Dalak palpe edilemedi ve perkütabl değildi. Genitoüriner sistem, lokomotor sistem ve sinir sistemi muayenesinde patolojik bulgu saptanmadi.

Tip 2 diabetes melitus ve pnömoni ön tanısıyla yapılan tetkiklerinde beyaz küre sayısı $13500 / \mathrm{mm} 3$, eritrosit sedimentasyon hizı $58 \mathrm{~mm} /$ saat, C-reaktif protein (CRP) 13,4 mg/l, kan şekeri $216 \mathrm{mg} / \mathrm{dl}$, aspartat aminotransferaz (AST) $124 \mathrm{U} / \mathrm{L}$, alanin aminotransferaz (ALT) $165 \mathrm{U} / \mathrm{L}$. yüksek, bilirubin değerleri normal sınırlardaydı. Tam idrar tetkikinde glukozürisi vardı. Hastada retinopati, nöropati, nefropati, koroner ve periferik arter hastalı̆̆ 1 tespit edilmedi.

Akciğer röntgenografisinde bilateral hiler genişleme ve interstisyel infiltrasyon bulguları mevcuttu (Şekil 1A). Solunum fonksiyon testinde (SFT) zorlu vital kapasite ('force vital capacity', FVC) 4,53 lt (\%82), zorlu ekspiratuvar-1 ('force expiratory volume' 1, FEV1):3,44 lt (\%76) ve FEV1/ FEVC oran1 \%74,46, difüzyon testinde difüzyon kapasitesi DLCO_SB:5,24 lt (\%42) idi. Hepatit ve human immunodeficiency virus (HIV) için seroloji testleri ve kollajen doku hastalığı akciğer tutulumu açısından romatoid faktör (RF), anti-ENA_SSB, anti-ENA_SSA, anti-ENA_jo_1, antiENA_scl_70, anti-ENA_Sm, anti-ENA_Sm_RNP negatifti. Antinükleer antikor (ANA) aktin paterni $1 / 1000$ pozitifti. Toraksın bilgisayarlı tomografisinde bilateral hiler ve mediastinal lenfadenopati ve interstisyel infiltrasyon mevcuttu.

Karaciğer enzim yüksekliği saptanan olgunun hepatobiliyer sonografisinde karaciğer normal lokalizasyonda, boyutu minimal artmış, dış konturu minimal lobule, parankimi hafif granuler ve periportal eko artısı izlendi. Belirgin yer kaplayan kistik ya da solid kitle lezyon izlenmemiş, portal ve hepatik venöz sistem normal genişlikteydi. Safra kesesi büyüklüğü ve duvar kalınlığı normal olup, taş ya da kitle izlenmedi. Antimitokondriyal antikor (AMA) ve anti düz kas antikoru (ASMA) negatif geldi. Karaciğer sirozu ön tanısıyla karaciğer biyopsisi planland.

Akciğerdeki lezyonlar ve lenfadenopati nedeniyle yapılan bronkoskopi ve bronkoalveolar lavajda (BAL) alveoler makrofaj yanında, artmıs lenfositler $(\% 34,1-\% 51,9)$ ve granülositler $(\% 11,9)$ görüldü. Analizde, CD4/CD8 oranı $5,46^{\prime}$ ve $\mathrm{CD} 4+\mathrm{CD} 103+$ hücrelerde artış bulundu. Akciğer görüntülemesinde bilateral mediastinal lenfadenopati olması, ateş, artralji şikayetlerinin bulunması, BAL sonucunda CD4/CD8 oranının 5,46 gelmesi ve deride eritema nodosum bulunması nedeniyle "Löfgren sendromu" tanısı konuldu. Tedavi amaciyla oral metil prednisolon $48 \mathrm{mg} /$ gün başland. İki haftada bir SFT/difüzyon testi ve akciğer grafisi ile kontrol edilerek doz azaltıldı. Tedavi başladıktan sonraki üç hafta içinde solunumsal semptomları 
düzeldi, eritema nodosum geriledi ve kayboldu. Takiben radyolojik düzelme tespit edildi (Şekil 1A,B).

Metilprednisolon $24 \mathrm{mg} /$ gün almakta iken sol kolda şişlik ve kızarıklık yakınması ile başvuran hastada olekranon bursiti saptandı ve cerrahi planlandı. Operasyon sonrasında ampirik ampisilin-sulbaktam ve siprofloksasin verildi. Enfeksiyöz durumla birlikte yüksek doz steroid almakta olan diyabetik olgunun metfromin ile kan şekeri regüle değildi. Glikozile hemoglobin (HBA1C, A1C) \%7,5 saptanmasına rağmen steroid tedavisi başladıktan sonra ve karaciğer enzimlerinin de artış gösterdiği dönemde kan şekerleri $250 \mathrm{mg} / \mathrm{dl}$ üzeri seyretmekteydi. Hastaya yoğun insülin tedavisi başlandı. Kan şekeri yüksekliği devam eden hastanın tedavisi insülin glarjin günlük $2 \times 34$ ünite, insülin glulisin $3 \times 24$ ünite subkutan olarak düzenlendi. Kronik aktif karaciğer hastalığı nedeniyle oral antidiyabetik kullanılamadı. Antibiyotikleri 15 güne tamamlanarak kesildi. Tekrar SFT / difüzyon testi ve akciğer grafisi ile değerlendirilerek metilprednisolon dozu 16 mg’a düşüldü. Takiplerinde kan şekeri 400 üzerinde seyretmesi üzerine insülin glarjin $54+50$ ünite ve insülin glulisin 3x36 ünite olarak düzenlendi. Steroid olarak verilen metilprednisolon 1x8 mg dozuna inildiğinde ve kesilme planı yapıldı. Kan şekerleri 200mg/dl altında seyretti.

Olgumuzun sarkoidoz semptomları, kliniği, laboratuvar ve görüntüleme bulguları steroid tedavisi ile geriledi ve kayboldu. Kronik aktif karaciğer hastalığı tanısal süreci için karaciğer biyopsi planı vardı. Bu arada steroid tedavisi ve karaciğer hastalığının aktif oluşu nedeniye tip 2 diyabetik hastada kan glukoz düzeylerinin kontrolü bazal-bolus insülin tedavisi yapıldı. Mikrovasküler ve makrovasküler komplikasyonları bulunmayan, sarkoidoz kliniği gerileyen olgu karaciğer tanı ve tedavisi süresince yoğun insulin tedavisi ile takibe alındı. Prednol $8 \mathrm{mg}$, azotiopurin $2 \times 50 \mathrm{mg}$, insülin glarjin 40 ünite ve insülin glulisin $3 \times 30$ ünite tedavisi ile izlenmektedir.

\section{TARTIŞMA}

Sarkoidoz nedeni bilinmeyen, sistemik, granülomatöz bir hastalıktır. En sık akciğerleri etkilerse de pek çok organ tutulabilir. Yapılan çalışmalarda en sık başlangıç yaşı 2040 yaşlar arası olarak saptanmıştır. Son yıllarda büyük gelişmeler olmasına karşın sarkoidoz immünopatogenezi hâlâ tam anlaşllamamıştır. Temel olay granülom gelişimidir. Olguların \%60'indan fazlasında hastalık kendini sinırlar ve granülomlarda spontan rezolüsyon olurken, bir grup hastada masif granülom oluşumu söz konusudur. Bir kısminda tedavi ile bile yanıt alınamayabilir. Radyolojik infiltratlar yaygin bile olsa olguların \%20'sinden daha azında ral duyulur. Çomak parmak nadirdir. İlerlemiş hastalıkta kor pulmonale gelişebilir. Sarkoidozda akciğer radyografisine göre radyolojik evreleme yapılmaktadır. Olguların büyük çoğunluğunun radyolojisi evre 1 veya 2 ile uyumludur. ACCESS çalışmasında olguların sadece $\% 15$ 'inde evre 3 veya 4 radyoloji izlenmiştir. Bilateral hiler lenfadenopatiye sık olarak sağ paratrakeal lenfadenopati eşlik eder. Parankimal infiltratlar yamalı veya diffüz olabilir, en sık üst ve orta zonlar tutulur. Genellikle retikülonodüler
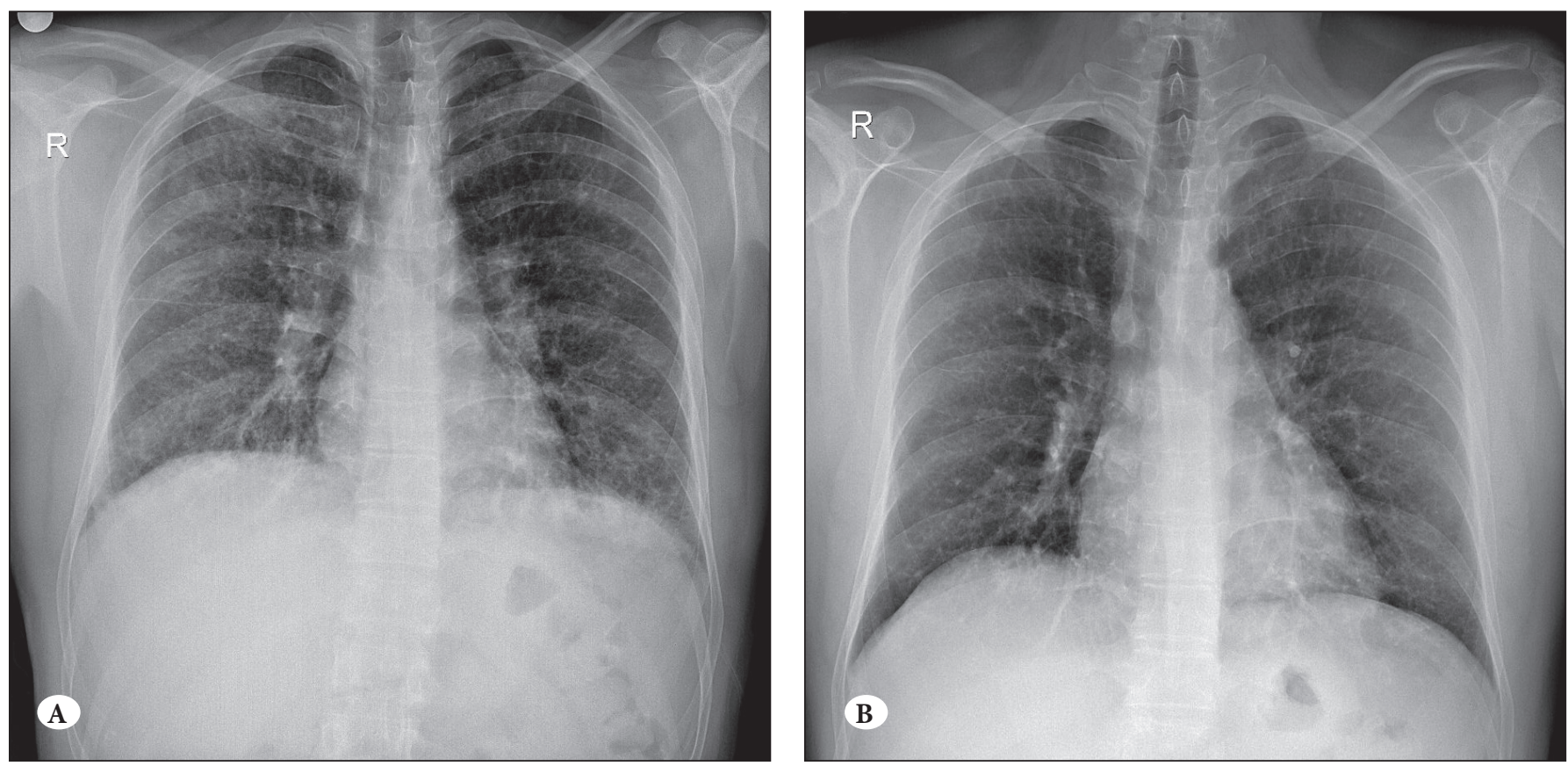

Şekil 1: Tedavi öncesi (A) ve sonrası (B) PA akciğer grafileri. Tedavi öncesi bilateral hiler genişleme ve interstisyel infiltrasyon bulguları tedavi sonrası gerilemiş ve kaybolmuştur. 
interstisyel infiltratlar görülür. En sik görülen bulgu perilenfatik dağılım gösteren, sınırları düzensiz 1-5 mm'lik küçük nodüllerdir. Nodüller daha çok üst ve orta zonlarda yerleşir, simetriktir $(2,5)$. Olgumuz diyabet tanısından birkaç yll sonra semptom, klinik bulgular, radyolojik, laboratuvar bulgularıyla tanı almış evre 2 sarkoidoz olgusudur.

Sarkoidoz birçok organı tutabildiği gibi karaciğer ve gastrointestinal sistemi de tutabilir. Karaciğer biyopsilerinde sık olarak granülom saptanabilir; ama hastaların çoğunun yakınması yoktur. Sarkoidozlu olguların \%10'unda karaciğer enzimleri yüksek çıkabilir. Karaciğer sarkoidozunun sıklıkla sessiz olmasına rağmen nadiren karaciğer tutulumuna bağlı kaşıntı, sarılık, karaciğer yetmezliği ve portal hipertansiyon gelişebilir. Karaciğer yetmezliği, hepatopulmoner sendrom, varis kanamalariyla seyreden portal hipertansiyon olguların \%1'den azında görülür (5). Diyabetik olgumuzda sarkoidozun karaciğer tutulumuna dair veriler kesin değildi. Steroid tedavisi sırasında karaciğer enzimlerinin yüksek seyretmesi farklı bir klinik tabloyu düşündürmüş ve karaciğer biyopsisi planlanmıștı.

Sarkoidoz tanısı için uyumlu klinik tablo varlığında, histolojik olarak kazeifikasyon nekrozu içermeyen granülomların gösterilmesi ve aynı tabloya yol açabilecek diğer nedenlerin dişlanması gerekir. Bronkoskopi yapılarak bronkoalveoler lavaj, bronş mukoza biyopsisi, transbronşiyal iğne aspirasyonu, transbronşiyal biyopsi alınabilir. BAL'da yüksek CD+/CD8 oranı tanıy destekleyen bir ipucudur. BAL'da lenfosit oranının \%15'in üzerinde olması \%90 sensitifdir ama özgüllüğü düşüktür. BAL CD4/ CD8 oranının $>3.5$ olmasının duyarlılığı \%53, özgüllüğü $\% 94$ 'tür. Serum ACE düzeyinin yüksekliği tanıya yardımcı olmakla beraber esas olarak aktivasyonu yansitır ve serum düzeyi granülom yükü ile ilişkilidir. Löfgren sendromu (ateş ve titreme, eritema nodosum, artralji ve bilateral hiler lenfadenopatinin görülmesi), Heerfort sendromu (ateş, parotis bezinde büyüme, anterior üveit ve fasiyal sinir felci) varlığında doku tanısı olmaksızın sarkoidoz tanısı konabilir $(2,5)$. Diyabetik olgumuz ateş, titreme, eritema nodosum, artralji ve bilateral hiler lenfadenopatinin eşlik ettiği Löfgren sendromu tablosu ile prezente olmuştur. Bronkoskopik işlem ve BAL sonuçlarıyla sarkoidoz tanısı ile steroid tedavisi kararı verilmiştir. Takipte olgumuza ait kan şekeri değerleri yükselmiş ve yoğun insulin tedavisi verilmiştir.

Sarkoidozda tedavi kararı hastanın semptomlarının şiddeti ve organ fonksiyonlarının bozulma derecesine göre verilir. Sarkoidoz tedavisinde kullanılan ajanlar çok etkin olsa da küratif bir tedavi sağlamamaktadır. Steroid tedavisi verilen hastalarda nüksler çok sık görülürken, tedavi almadan iyileşen olgularda nüks çok nadirdir. Evre I, semptomsuz olgular tedavisiz izlenmektedir. Evre II ve III olguların 6 ay süreyle tedavisiz izlendiği bir çalışmada olguların \%20'sinde spontan düzelme olurken, $\% 40$ 'inda bozulma gözlenmiş ve steroid başlanması gerekmiştir (6). Tedavi başlandığı zaman olguların önemli bir kısmına uzun süre tedavi gerekmektedir. Başlangıç dozu olarak günde prednizon 30-40 mg yeterli görülmektedir; fakat ağır kardiyak ve nörolojik tutulumu olan olgularda daha yüksek dozlar gerekebilir. Akciğer sarkoidozunda $20 \mathrm{mg}$ üzeri dozların gerekmediğini bildirenler de vardır. Steroid dozunun azaltılma hızı ile ilgili değişik öneriler vardır. Ancak toplam tedavi süresinin en az bir yıl olması genel olarak kabul edilmektedir. Steroid kesildikten sonra nüks oranları \%70'lere yaklaştı̆̆ı için steroid azaltma döneminde ve steroid kesildikten sonra hastaların yakın izlemi önemlidir. Genellikle 4-8 haftada tedaviye yanıt alınır. Üç ayda yanıt vermeyen olgular steroide dirençli kabul edilmeli ve tedavi kesilmelidir. Steroid tedaviye alternatif olarak klorokin/ hidroksiklorokin, sitotoksik - immünsüpressif ilaçlar (metotreksat, azatioprin, siklofosfamid, leflunamid) ve TNF- $\alpha$ antagonisti monoklonal antikorlar kullanılabilir(7). Diyabetik olgumuzda metilprednisolon $1 \times 48 \mathrm{mg} / g u ̈ n$ steroid tedavisine üç hafta gibi kısa sürede klinik, radyolojik ve laboratuvar yanıt alınmıştır. Takip eden dönemde azotiopurin tedaviye eklenmiştir. Ancak bu sürede kan şekeri kontrolünü sağlamada zorluk çekilmiştir. Ek olarak karaciğer patolojisi öne çıkmıştır.

Glukokortikoidlerin birçok yan etkisi mevcuttur. Bunlardan bazıları kilo alma, iyatrojenik Cushing sendromu, deri lezyonları, hiperglisemi, diabetes mellitus, hiperlipidemi, ateroskleroz, hipopotasemi, sodyum tutulumu, ödem, hipervolemi, menstruasyon düzensizliği, amenore, empotans, osteoporoz, aseptik nekroz, miyopati, enfeksiyon riskinde artış, psikoz, katarakt gelişimi, ateroskleroza ve venöz tromboza eğilim görülmesidir. Glukokortikoidler gibi günümüzde sıklıkla kullanılan bazı ilaçlar daha önce diyabeti bulunmayan kişilerde hiperglisemiye neden olmakta, bilinen diyabetiklerde ise glisemik kontrolün bozulmasına yol açmaktadır (8).

Mevcut literatürde 1950-2009 yılları arasında yayınlanan glukokortikoidlerin neden olduğu hipergliseminin diabetes mellituslu ve diyabetsiz hastalar arasında yaygın olduğu, glukokortikoidlerin kümülatif dozu ve tedavi süresinin diyabet gelişimini predikte ettiği ve yeni başlangıçlı diyabeti daha fazla ortaya çıkardığı (odds ratio 1,5-2,5) bildirilmiştir (3). Glisemi üzerine steroidlerin etkisi farklı mekanizmalarla açıklanmaktadır. Özellikle hepatik glukoneogenezdeki enzimlerin induksiyonu, periferik dokularda glukoz alıminda azalma, lipolizin uyarılması, insulin sekresyonunun azaltması ve insulin direncine neden olan seramidlerin biyosentezini arttırarak glisemi düzeylerini değiştirmektedir $(9,10)$. 
Glukokortikoidler post-reseptör mekanizmaları etkileyerek periferik ve kısmen hepatik insülin duyarlılığını azaltırlar. Bilinen diyabetlilerde yüksek doz prednizolon $(\geq 30 \mathrm{mg} /$ gün) kullanılması glisemik regülasyonu bozar ve kısa etkili insülin gereksinimini artırır. Fizyolojik dozun üzerinde (>7.5 mg/gün) prednizolon kullanan hastalarda ortaya çıkan insülin rezistansı ve hiperglisemi ilaç kesildikten sonra normale dönebilir. Glukokortikoid kullanan ve daha önceden diyabeti olmayan kişilerin \%14-28'inde BGT veya diyabet ortaya çıkmaktadır. Oral glukoz tolerans testinde (OGTT) glukoza insülin yanıtı azalır. Glukokortikoid kullanımına bağlı diyabette OAD veya daha iyisi insüline geçilmelidir. Yüksek doz glukokortikoid kullanan diyabetlilerde insüline geçilmesi gerekir. Daha önceden insülin kullanan diyabetlilerde dozun \%50 kadar yükseltilmesi gerekir (3,4,8,10-12). Diyabetik olgumuzda sarkoidoz tanısı konmadan önce beslenme, yaşam tarzı değişikliklerine dikkat ederek ve metformin ile metabolik kontrol sağlanmaktaydı. Steroid tedavisine başlandığında artan insulin ihtiyacı ile metabolik kontrol sağlanmaya çalışılmıştır. Karaciğer enzimlerinde üç katından fazla artış bulunması nedeniyle insulin direncinde artış olmasının yanında oral antidiyabetiklere kontrendikasyon durumu gelişmiştir. Tedavide insulin ihtiyacı günlük ihtiyacın 10 katını geçmiştir.

Kim ve ark.nın yaptığı bir çalışmada 2003-2008 yılları arasında kronik akciğer hastalıklarında son 4 hafta boyunca en az $20 \mathrm{mg} /$ gün prednizona eşdeğer glukokortikoid alan hastalar incelenmiştir. Bu çalışmada başlangıçta diyabet tanılı olanlar ve kan şekeri $200 \mathrm{mg} / \mathrm{dL}$ üzerinde olan hastalar çalışmadan çıkarılmış ve steroide bağlı diabetes mellitus; steroid tedavisine başlandıktan sonra açlık glikoz konsantrasyonu $126 \mathrm{mg} / \mathrm{dL}$ 'yi veya rastgele bir glikoz konsantrasyonunu en az iki kez $200 \mathrm{mg}$ / dL'yi aşan değerler olarak tanımlanmıştı. Bu çalışmada toplam 231 hastanın 34 'ünde (\% 14.7) steroide bağlı diabetes mellitus rapor edilmiştir (13).

Steroidle indüklenen hiperglisemi yatan hastalarda yaygındır. Yüksek doz steroid tedavisinin başlaması üzerine hastalar hiperglisemi açısından izlenmeli ve tedaviye başlanmalıdır (14). Hastanede steroid kaynaklı hiperglisemi başlangıçta hızlıdır ve hemen hemen her zaman 1-2 gün içerisinde gelişir. Bu nedenle ilk 48 saatteki glikoz testi ile hiperglisemi olanların çoğu saptanır(14-16). Oral anti diyabetik ajanların, steroidle indüklenen diyabetli ayaktan hastalar için uygun tedavi olabileceği konusunda bazı literatürler vardır $(17,18)$. Ancak hipergliseminin şiddeti hastaneye yatırılmış hastalarda insulin genellikle gerekli olmaktadır. Prednizolon ile tedavi edilen $\mathrm{KOAH}$ hastalarında sürekli kan glikoz monitörünün kullanılması, öğleden sonra ve akşam hipergliseminin baskın olarak gerçekleștiğini göstermiştir. $\mathrm{Bu}$, steroide bağlı diabetes mellitus için taramanın yanı sıra doğrudan spesifik tedaviye en uygun zamana işaret etmektedir $(15,19$.)

Oral kortikosteroid alan akciğer hastalığ 1 olan bireylerin eşleşmiş kontrol grubuna göre kırık riskinde önemli farklılıklar ve diğer olumsuz etkileri gösterilmiştir. $\mathrm{Bu}$ yan etkiler çoğunlukla prednisolonun kümülatif dozuyla ilişkilendirilmiştir (20). Otoimmün hastalıklar için 1940'lı yıllarda glukokortikoid tedavinin başlangıcından bu zamana kadar yaygın uygulanması birçok olumsuz metabolik yan etkiye ve eşzamanlı tedaviyi sınırlayıcı nedenlere yol açmıştır. Glukokortikoidlerin başlanması ile ilişkili beklenmedik hiperglisemi, katı organ nakli alan hastalarda hastaneye yatışların, hastanede kalıs sürelerinin uzamasına, enfeksiyon riskinde artışa ve greft fonksiyonlarında azalmaya da yol açabilmektedir. Steroid ile indüklenen diyabetin yönetiminde karşılaşılan zorluklar postprandiyal hiperglisemide geniş dalgalanmalara yol açmasının yanında açıkça tanımlanmış tedavi protokollerinin eksikliğine bağlıdır. Tedavinin başlıca dayanağı, yemeklerle çakışan insülin tedavisinin yapılmasıdır (19,21-23). Daha yaşlılar, yüksek HbA1c seviyesi ve düşük eGFR'ye sahip hastalarda uygulanan glukokortikoidlerin dozuna bakılmaksızın steroide bağlı hiperglisemi/diabetes mellitus gelişimi yakından izlemeyi gerektirir (24)

Yüksek doz ve uzun süre glukokortikoid kullanımı ve diabetes mellitus birlikteliği kronik akciğer hastalıklarında kan şekeri kontrolünün bozulmasına ve diabetes mellitusa bağlı komplikasyonların artışına neden olabilmektedir. Bu durum deneyimli kliniklerde dahi önemli sorunlar teşkil etmektedir. Diabetes mellituslularda tedaviyi aksatmadan glukokortikoid dozunun mümkün olan en hızlı sürede en düşük doza düşülmesi veya yerine alternatif tedaviler kullanılması kan şekerinin kontrolünde önemli rol oynayacaktır.

\section{KAYNAKLAR}

1. De Bosscher K, VandenBerghe W, Haegeman G. Mechanisms of antiinflammatory action and of immunosuppression by glucocorticoids: negative interference of activated glucocorticoid receptor with transcription factors. J Neuroimmunol 2000; 109: 16-22.

2. Iannuzzi MC, Rybicki BA, Teirstein AS. Sarcoidosis. N Engl J Med 2007; 357: 2153-2165

3. Clore JN, Thurby-Hay L. Glucocorticoid-induced hyperglycemia. Endocr Pract 2009;15:469-74.

4. American Diabetes Association. Standards of medicalcare in diabetes-2015. DiabetesCare 2017;40(Suppl.1):S11-S24.

5. Namzeh N. Sarcoidosis. MedClin North Am 2011; 95: 1223-34

6. Musellim B, Kumbasar OO, Ongen G, et al. Epidemiological features of Turkish patients with sarcoidosis. RespirMed 2009; 103: $907-12$ 
7. Jara-Palomares L, Caballero-Eraso C, Díaz-Baquero A, Rodríguez-Portal JA. (2011). Updated Guidelines for the Treatment of PulmonarySarcoidosis, Sarcoidosis Diagnosisand Management, Prof. Mohammad Hosein Kalantar Motamedi (Ed.), InTech, DOI: 10.5772/22760. Available from: https:// www.intechopen.com/books/sarcoidosis-diagnosis-andmanagement/updated-guidelines-for-the-treatment-ofpulmonary-sarcoidosis (Accessed Date 19.11.2017).

8. National Institute for Health and Clinical Excellence (NICE). Type 2 diabetes in adults: management. NICE guideline [NG28]Publisheddate: December 2015 Last updated: May 2017. https://www.nice.org.uk/guidance/ng28 (AccessedDate: 19.11.2017)

9. Kleiman A, Tuckermann JP. Glucocorticoid receptor action in beneficial and side effects of steroid therapy: lessons from conditional knockout mice. Mol Cell Endocrinol. 2007;275(12):98-108.

10. 10-50. Clore JN, Thurby-Hay L. Glucocorticoid-induced hyperglycemia. Endocr Pract. 2009;15(5):469-74.

11. Álvarez-Rodríguez E, Agud Fernández M, Villa Álvarez MC, Caurel Sastre Z, Gallego Mínguez I, Carballo Cardona C, Juan Arribas A, Piñero Panadero R, Rubio Casas O, Sáenz Abad D, Cuervo Pinto R.[Recommendations for the management of emergencies in patients with diabetes, acute metabolic complications of diabetes, andsteroid-related hyperglycemia]. Emergencias. 2016;28(6):400-417.

12. 12-Gannon C, Dando N. Dose-sensitive steroid-induced hyperglycaemia. Palliat Med. 2010;24(7):737-9.

13. Kim SY, Yoo CG, Lee CT, Chung HS, Kim YW, Han SK, Shim YS, Yim JJ. Incidence and risk factors of steroid-induced diabetes in patients with respiratory disease. J Korean Med Sci. 2011;26(2):264-7.

14. Fong AC, Cheung NW. The high incidence of steroid-induced hyperglycaemia in Hospital. Diabetes Research And Clinical Practice 2013; 99:277- 280.

15. Burt MG, Roberts GW, Aguilar-Loza NR, Frith P, Stranks $\mathrm{SN}$. Continuous monitoring of circadian glycemic patterns in patients receiving prednisolone for COPD. J Clin Endocrinol Metab 2011;96:1789-996.
16. Umpierrez GE, Hellman R, Korytkowski MT, Kosiborod M, Maynard GA, Montori VM, et al. Management of hypeglycemia in hospitalized patients in non-critical care setting: an endocrine society clinical practice guideline. J ClinEndocrinolMetab 2012;97:16-38

17. Clore J, Thurby-Hay L. Glucocorticoid-inducedhyperglycemia. EndocrinolPract 2009;15:469-74.

18. Tanaka K, Okada Y, Mori H, Torimoto K, Arao T, Tanaka Y. The Effects of Mitiglinide and Repaglinide on Postprandial Hyperglycemia in Patients Undergoing Methylprednisolone Pulse Therapy. InternMed. 2018;57(1):65-70.

19. Hwrang JL, Weiss RE. Steroid-induced diabetes: a clinical and molecular approach to understanding and treatment. Diabetes Metab Res Rev. 2014; 30(2): 96-102.

20. Walsh LJ, Wong CA, Oborne J, Cooper S, Lewis SA, Pringle M, Hubbard R, Tattersfield AE. Adverseeffects of oralcorticosteroids in relationtodöşe in patientswith lungdisease.Thorax. 2001;56(4):279-84.

21. Perez A, Jansen-Chaparro S, Saigi I, Bernal-Lopez MR, Miñambres I, Gomez-Huelgas R. Glucocorticoid-induced hyperglycemia. Journal of Diabetes 2014;6;9-20.

22. Raalte DH, Diamant M. Steroid diabetes: from mechanism to treatment? Netherlands The Journal of Medicine 2014; 7 2(2):62-72.

23. Gerards MC, Tervaert EC, Hoekstra JB, Vriesendorp TM, Gerdes VE. Physician's attitudes towards diagnosing and treating glucocorticoid induced hyperglycaemia: Sliding scale regimen is stil widely used despite guidelines. Diabetes Res Clin Pract. 2015;109(2):246-52.

24. Katsuyama T, Sada KE, Namba S, Watanabe H, Katsuyama E, Yamanari T, Wada J, Makino H. Risk factors forthe development of glucocorticoid-induceddiabetesmellitus. Diabetes Res Clin Pract. 2015;108(2):273-9. 

